\title{
Segmental Versus Circumferential Ablation of Pulmonary Veins in Patients with Paroxysmal Atrial Fibrillation
}

\author{
Ahmed Moustafa Wedn ${ }^{1 *}$, Ahmed Eldamaty $^{2}$, Moataz Elhalag $^{1}$, Rania Elsherif $^{1}$, Hesham Alaasar $^{1}$ \\ ${ }^{1}$ Department of Critical Care, Cairo University, Egypt; ${ }^{2}$ Department of Cardiology, Cairo University, Egypt
}

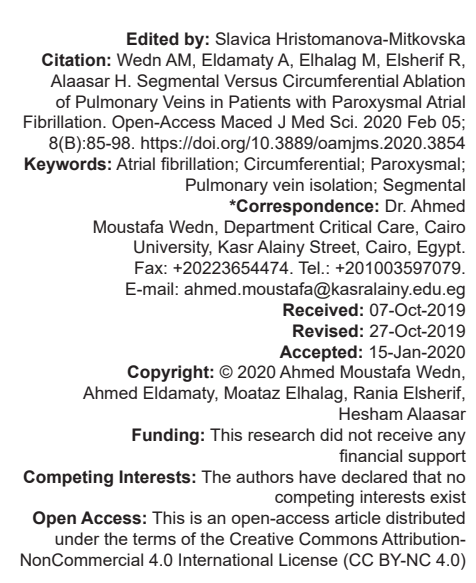

\section{Introduction}

Catheter ablation of atrial fibrillation $(A F)$ has its roots in the surgical Maze procedure to cure AF developed by Cox [1]. The Maze procedure consists of a series of incisions in the right and left atria designed to develop anatomic barriers to conduction that would prevent maintenance of AF. This approach was patterned on the substrate-based mechanism of AF - the multiple wavelet theory of Moe [2]. According to this theory, large portions of the atria are involved in the development of multiple reentrant circuits that exist simultaneously to maintain AF. Therefore, the surgical procedure erects "road blocks" designed to prevent the perpetuation of these reentrant circuits.

The Maze surgery is reasonably effective but has not been accepted as a routine clinical technique [3]. An important part of the Maze technique is the isolation of the pulmonary vein (PV). In fact, in retrospect, this may have been the key to the success of the procedure [4]. More recent observations since the late 1990s from Haïssaguerre et al. [5] have demonstrated that the initiators of AF typically originate in the PVs, and isolation of these veins often prevents AF. This observation supports the ectopic focus theory of AF proposed by Scherf et al. decades ago [6]. It is now known that rapidly firing foci can occur outside of the PVs such as the superior vena cava, coronary sinus, and less commonly other areas in the right and left atria.

The initial catheter ablation approach attempted to mimic the Cox surgical Maze procedure and consisted of multiple linear ablation lines introduced in the right and left atria. Success was not high, and serious complications were too frequent. The realization that in humans, at least in patients with paroxysmal AF (PAF), the $P V s$ are the prime initiating focus of AF has led to $a$ sea change in the ablation approach to curing AF.

Currently, the primary objective is to isolate the PVs from the left atrium (LA). In patients with 
long-standing persistent AF, left atrial tissue outside of the PVs may play a prominent role in the maintenance of $A F$, and this requires additional ablation lesions. In essence, the respective role of initiator and substrate to maintain AF is clearly not distinct in many patients, and various patient subgroups may require combined ablation approaches to achieve a successful outcome.

\section{Methodology}

This is a prospective randomized controlled clinical trial that was conducted between May 2015 and May 2017 and under follow-up for 1 year, in the Critical Care Medicine Department - Cairo University. Our study design involved 17 patients in Group I, age (53.76 $\pm 5.71)$, sex (11 males, and 6 females), left ventricular ejection fraction (LVEF) (57.59 \pm 5.79$)$, left atrial diameter (LAD) $(4.05 \pm 0.22)$, hypertension (6 patients, $35.3 \%$ ), and diabetes mellitus (DM) (5 patients, $29.4 \%$ ). Our study design involved 14 patients in Group II, age $(54.14 \pm 6.14)$, sex ( 7 males, and 7 females $)$, LVEF $(59.07 \pm 5.30), \operatorname{LAD}(3.93 \pm 0.21), \mathrm{HTN}$ (5 patients $35.7 \%$ ), and DM (2 patients, 14.3\%).

Our primary endpoints were to evaluate the recurrence rate, procedure data, and major complications related to circumferential versus segmental PVs isolation after the first AF ablation procedure. Secondary endpoints included identifying (1) other possible predictors of AF recurrence after ablation, and (2) determinants of predictors of increasing fluoroscopy time, mapping time, and procedure time.

\section{Inclusion criteria}

The following criteria were included in the study:

- $\quad$ Patients known to have PAF refractory to at least one antiarrhythmic drug.

- $\quad$ Patients who are maintained on sinus rhythm by medications.

- Patients $>18$ years old.

\section{Exclusion criteria}

The following criteria were excluded from the study:

- $\quad$ Patients with medical conditions that would limit participation for the entire study duration (diseases with life expectancy $<1 \mathrm{y}$ )

Patients having the previous stroke

Patients with persistent/permanent AF

Congestive heart failure

LA diameter $>5.5 \mathrm{~cm}$.

Uncontrolled thyrotoxicosis or ischemic heart disease.
For all patients enrolled in the study, demographic and clinical data were recorded, including AF symptomatic details, electrocardiograms (ECGs), Echo, and computed tomography (CT) scan (if possible). The consent from all patients was signed before the procedure and after explaining all procedure steps and potential complications according to European guidelines 2016 [7], American guidelines 2017 [8].

\section{Pre-procedural preparations}

There were two pre-procedural protocols for anticoagulation according to operator preference; Warfarin was discontinued before the procedure for at least 5-7 days, with bridging with low-molecular-weight heparin (LMWH) for 3 days before ablation, allowing international normalized ratio (INR) to drop to normal (or near normal <1.2) level on the day of ablation. In this protocol, LMWH was discontinued on the night before the procedure and restarted $6 \mathrm{~h}$ after procedure along with Warfarin, provided adequate hemostasis. Once INR had risen to 2-3, LMWH was discontinued.

The other protocol involves continuing Warfarin or NOAC without interruption and performing the procedure on therapeutic INR of 2-3.

The absence of LA thrombus was confirmed by a transesophageal echocardiogram.

According to our study protocol, antiarrhythmic medications (Amiodarone) were continued for at least 3 months after the procedure (the blanking period).

\section{Procedure}

On the day of the procedure, all patients signed informed written consent.

\section{Patient monitoring during the procedure}

Surface ECG and bipolar endocardial electrograms were stored continuously using multichannel polygraph (Lab System PRO ${ }^{\circledR}$, Bard Electrophysiology or WorkMate Claris ${ }^{T M}$, St. Jude) for further analysis. Bipolar recordings were filtered from 30 to $500 \mathrm{~Hz}$. Arterial blood pressure (BP) and $\mathrm{SpO}_{2}$ were continuously monitored. All patients had the procedure done under conscious sedation (Midazolam, induction by $0.3 \mathrm{mg} / \mathrm{kg}$ bolus dose over 20-30 s, and maintenance by $0.05 \mathrm{mg} / \mathrm{kg}$ boluses if needed), local anesthesia (lidocaine HCL 2\%, $400 \mathrm{mg}$ intradermal), and analgesics (Paracetamol, $1000 \mathrm{mg} \mathrm{IVI}$ over $3 \mathrm{~h}$, Morphine 2-4 mg repeated $1-2 \mathrm{~h}$ if needed with maximum cumulative dose $10 \mathrm{mg}$ ).

\section{Trans-septal puncture}

Trans-septal puncture was guided by fluoroscopy and multipolar catheter placed in coronary 
sinus. In addition, aortic root was marked by either his catheter or pigtail catheter placed retrogradely at the aortic root. One or Two 8F long sheaths (Mullin or preface) were then placed in LA through the puncture (Figure 1).

Few cases (3 patients) trans-septal were done under the guidance of Intra Cardiac Echo, according to operator choice.

In 11 patients, transesophageal echo was used for trans-septal puncture.

\section{Description of the procedure}

Following trans-septal puncture, weightadjusted unfractionated heparin (UFH) was administered to achieve an ACT of 300-350. ACT was then repeated every 15-30 min, and UFH was given accordingly to maintain the measurements within the target.

\section{Mapping}

We defined mapping time as the time from inserting circular map catheter till definition of all PVs using the $3 \mathrm{D}$ navigation system in most of cases (25 patients, 80.7\%), CARTO3 (Biosense Webster, Johnson and Johnson), or NavX, (EnSite Velocity, St. Jude) was used for LA shell construction.

In other patients, (6 patients 19.3\%), PVs were mapped conventionally by fluoroscopy.

Marking of PVs and ostia delineation were carefully done before the procedure to have an idea about the anatomy of the PVs and detecting the antrum; we applied three methods for that:

1. Merging of CT angiography of LA with electroanatomical map (12 patients, 38\%)

2. Selective pulmonary angiography or LA angiography (5 patients, 16\%). We used multipurpose catheter and $10 \mathrm{cc}$ of contrast without dilution and manually inject it in each PV (in selective pulmonary angiography) or in LA and record it on fluoroscopy. $P V$ is a funnel shaped, with a tube that fans out into a proximal "cup" that blends into the posterior atrial wall, which we refer to as the antrum [9], (Figure 1)

3. When the previous two methods were not available or not conclusive (14 patients, $45 \%$ ), we were depending on the impedance difference between the vein, which is high (>190 $\pm 45 \mathrm{ohm})$ and the LA (<120 $\pm 30 \mathrm{ohm})$. We mark the best place by a circular map and record it on fluoroscopy.

In our study, we found 6 patients (19.4\%) with left common ostium, and 3 patients $(9.7 \%)$ with the absence of right inferior $\mathrm{PV}$.

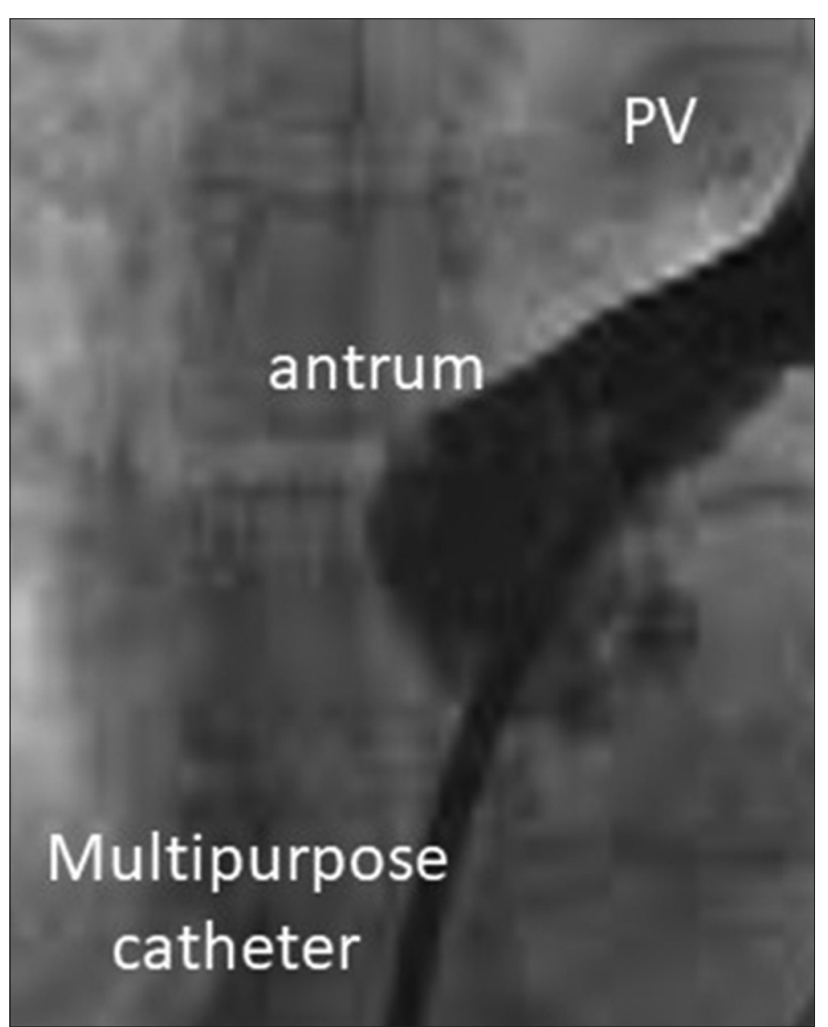

Figure 1: Angiography for $L S P V$, showed a funnel-shaped PV, a tube (PV) that fans out into a proximal "cup" (antrum), LSPV: Left superior pulmonary vein, PV: Pulmonary vein

\section{Radio frequency (RF) ablation}

A fully expanded 10-pole (electrode width $1 \mathrm{~mm}$, inter-electrode distance $8 \mathrm{~mm}$ ) or 20-pole (electrode width $1 \mathrm{~mm}$, inter-electrode distance is 2-5-2 mm) circular mapping catheter (Lasso 2515, Biosense Webster, Diamond Bar, CA, USA) was then placed as proximal as possible in $\mathrm{PV}$ ostium, and the vein was isolated by either circumferential or segmental by RF ablation extra ostial. Patients were randomized for the ablation approach according to admission ID.

\section{Circumferential PV isolation (PVI)}

Ipsilateral PVs were encircled as a unit by a common lesion, except for 2 patients, in whom right inferior PV was absent. Continuous lesions were always completed (Figure 2), and if PV disconnection was not achieved after completion of the PV encircling, conduction gaps in the circumferential lesion were identified, and ablation was continued until full PV disconnection was achieved.

There was no any addition of ablation lines in all patients.

\section{Segmental PVI}

In our study, we have 14 cases with segmental ablation. Eight patients were done guided by electroanatomical map, where the ablation targeting myocardial LA-PV breakthroughs (Figures 3 and 4). 


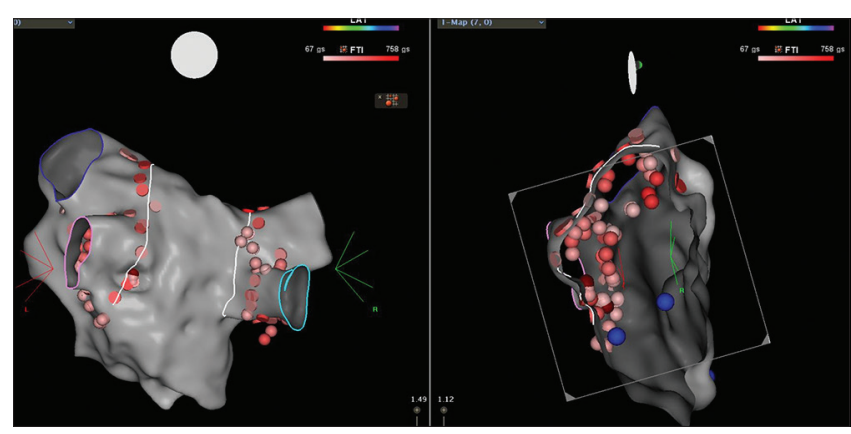

Figure 2: Posterior and modified clipped RL view of FAM of the left atrium showed circumferential ablation of pulmonary vein isolation. FAM: Fast anatomical map. RL: Right lateral

Other six patients were done conventionally and ablation was guided by the circular catheter. The RF energy was applied as proximal as possible but carefully extra ostial - detected previously during mapping - by adjusting it behind circular catheter on fluoroscopy (Figure 5).
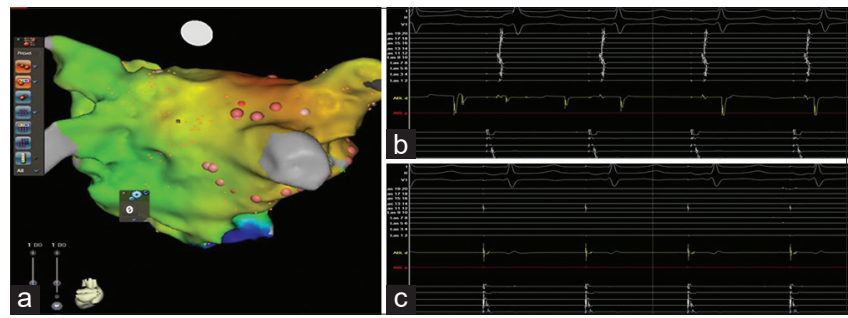

Figure 3: 20 poles lasso is placed at RSPV. (a) Posterior view of activation map of left atrium showing segmental ablation points at RPVs. (b) RSPVs before ablation. (c) RSPVS after pulmonary vein isolations. RSPV: Right superior pulmonary veins. RPVs: Right pulmonary veins

Ablation was finished at the moment of stable complete PV disconnection. Thus, RF energy applications did not inevitably cover the entire circumference of the PV ostia.

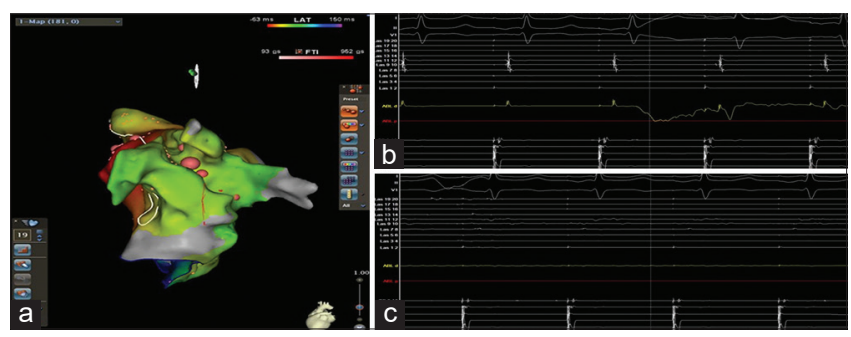

Figure 4: 20 poles lasso is placed at LSPV. (a) LL view activation map of left atrium showing segmental ablation points at the left ridge. (b) LSPV before ablation. (c): LSPV after ablation. LL: Left lateral, LSPVs: Left superior pulmonary veins

In most patients, standard $3.5 \mathrm{~mm}$ irrigated-tip ablation catheter was used; however, pressure-sensing $3.5 \mathrm{~mm}$ irrigated-tip catheter (Thermocool ${ }^{\circledR}$ SmartTouch $^{\circledR}$ catheter, Biosense Webster) was sometimes used (9 patients, 29\%).

Whenever the pressure-sensing catheter was used, all attempts were made to keep tip pressure between 10 and $30 \mathrm{~g}$ all through RF applications. The energy delivered for all catheters was $25 \mathrm{~W}$ on the posterior wall and roof of LA and $30 \mathrm{~W}$ elsewhere.

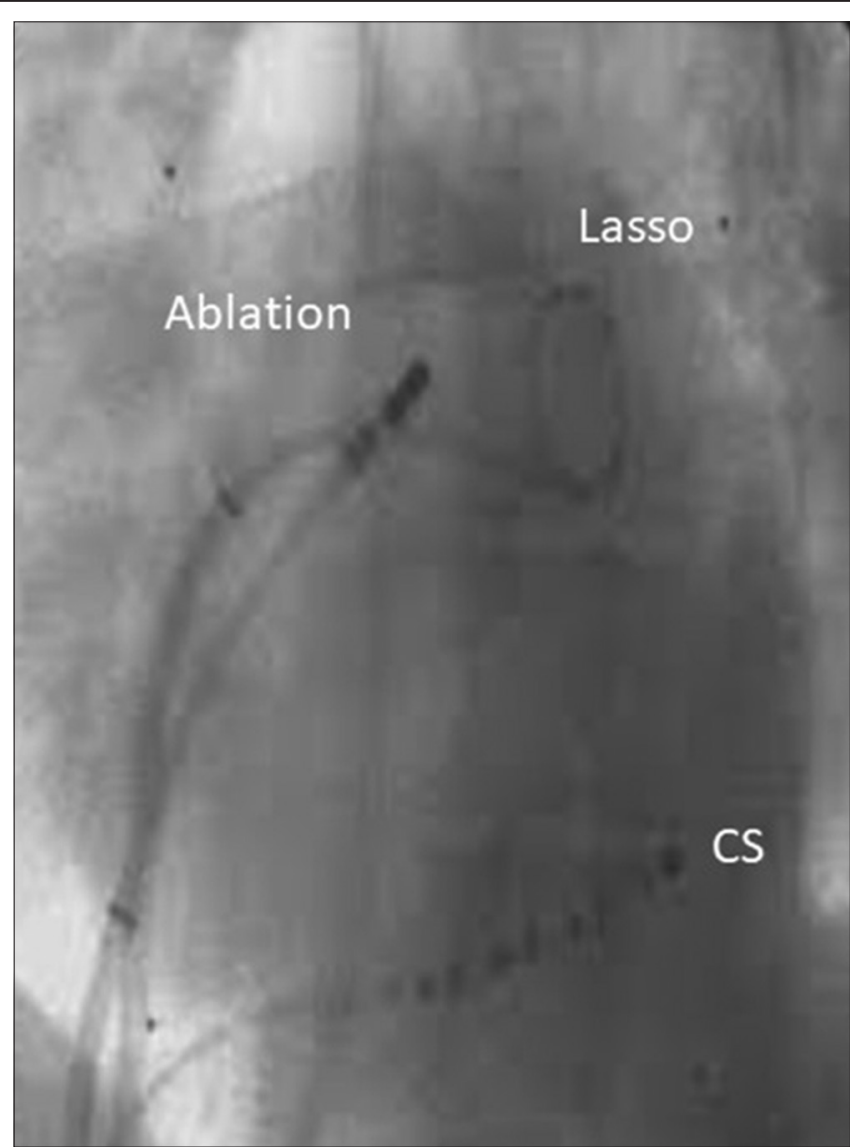

Figure 5: LAO fluoroscopic view showed conventional segmental ablation of LSPV. LAO: Left anterior view. LSPV: Left superior pulmonary vein

Ablation catheter was continuously irrigated using Heparinized Saline at the background rate of $2 \mathrm{ml} / \mathrm{min}$ that increases to $17 \mathrm{ml} / \mathrm{min}$ during RF application. RF energy was applied with a Stockert (Biosense-Webster, Diamond Bar, CA, USA) generator.

In all cases, Full PV isolation was defined as complete elimination of all high-frequency PV potentials recorded by the ring catheter during SR or atrial pacing, demonstration of entrance block into the vein was a mandatory endpoint. After isolating all veins that demonstrated PVP's, veins were re-checked at least 20 min later for gaps.

According to operator discretion, adenosine was sometimes given to unmask dormant conduction into PV, when found. Adenosine was given after $20 \mathrm{~min}$ of $\mathrm{PVI}$, at a dose that produced complete AV block or $3 \mathrm{~s}$ pause (Figure 6). We had 3 patients with spontaneous induction of AF at beginning and during the procedure (1 in circumferential group and 2 in segmental group) and remained at the end of PVI. There were electrically cardioverted, and all veins were re-checked in sinus rhythm.

At the end of the procedure, protamine was given, at operator discretion if last ACT > 250 to reverse the effect of heparin. Catheters were removed and hemostasis was ensured by compression plus figure of eight closure of puncture site if needed. Procedure 


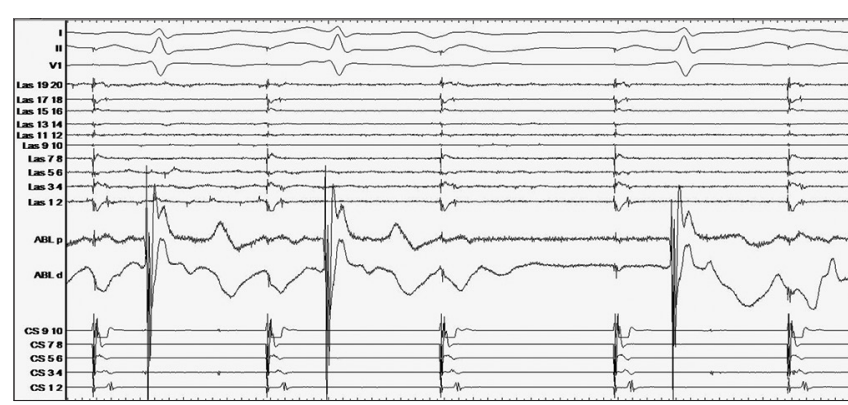

Figure 6: Adenosine $12 \mathrm{mg}$ injection after $20 \mathrm{~min}$ of left superior pulmonary vein isolation, showed no dominant conduction

time (from skin puncture to removal of sheaths) and fluoroscopy time were recorded.

\section{Post-procedural management}

Echo was done routinely for all patients after ablation and once patients arrive at the ward, ECG was continuously monitored. Twelve-lead ECG was recorded, along with all vital signs. According to the protocol, oral anticoagulation was resumed on the night of the procedure, provided adequate hemostasis, along with antiarrhythmic medication. If there were no complications, patients were discharged on the following day after ensuring stable hemodynamic and receiving post-ablation instructions and follow-up plans.

\section{Follow-up, monitoring of recurrence}

All patients were instructed to continue the same antiarrhythmic medication they used before ablation, for a minimum of 3 months (blanking period).

All patients had routine follow-up visits after 1 month, 3 months, 1 year, and in each visit, detailed history and 12 leads ECG was done for confirmation of sinus rhythm (normal sinus rhythm) and for any attack of palpitations during this period. If the attack was too short to be recorded, a 24-48 h Holter was done.

At the end of blanking period, all patients, who did not experience any palpitations in the blanking period, had at least $24 \mathrm{~h}$ Holter and if it was free, antiarrhythmic medication would be stopped.

Regarding anticoagulation, the decision of stopping is depending mainly on CHA2DS2VASC.

At the end of 1 year after ablation, all patients without documented AF recurrence after the blanking period had a 12-lead ECG and at least $24 \mathrm{~h}$ Holter. In our study, AF recurrence was defined as documented AF/AT episode longer than $30 \mathrm{~s}$ with or without symptoms.

In each of the two follow-up visits, patients were also asked and examined for possible complications related to ablation such as thromboembolism, PV stenosis, phrenic nerve injury, and atrioesophageal fistula.

\section{Statistical methods}

Data were coded and entered using the statistical package SPSS version 25. Data were summarized using mean and standard deviation for quantitative variables and frequencies (number of cases) and relative frequencies (percentages) for categorical variables. Comparisons between groups were done using unpaired t-test when comparing two groups and analysis of variance (ANOVA) with multiple comparisons post hoc test when comparing more than 2 groups [10]. For comparing categorical data, Chi-square $\left(\chi^{2}\right)$ test was performed. Exact test was used instead when the expected frequency is $<5$ [11]. Correlations between quantitative variables were done using the Pearson correlation coefficient [12]. $p<0.05$ was considered as statistically significant.

\section{Results}

Our study included 31 consecutive patients who underwent their first radiofrequency ablation for PAF between March 2015 and March 2017, and 1 year follow-up, in Critical Care Medicine Department - Cairo University. In all cases, PVI confirmed by the entrance block was a standard target. All patients were followed up for a minimum of 1 year. According to the study protocol, patients were randomized for circumferential or segmental ablation on the day of the procedure.

We had two groups, circumferential group (17 patients) and segmental group (14 patients).

Mapping of LA and PVs was done by 3D electroanatomical map, or conventionally by fluoroscopy.

Our primary endpoint was to study the effect of the two strategies of ablation circumferential versus segmental on the recurrence.

\section{Group characteristics}

Characteristics of study population and study groups are listed in Table 1.

Table 1: Characteristics of the study population and study groups

\begin{tabular}{|c|c|c|c|c|}
\hline Variable & All $n=31$ & $\begin{array}{l}\text { Group } 1 \\
\text { (circumferential) } n=17 \\
(54.8 \%)\end{array}$ & $\begin{array}{l}\text { Group } 2 \text { (segmental) } \\
\mathrm{n}=14(45.2 \%)\end{array}$ & $p$ \\
\hline Age (years) & $53.9 \pm 5.8$ & $53.7 \pm 5.7$ & $54.1 \pm 6.1$ & $>0.05$ \\
\hline Gender (M) & $18(58.1 \%)$ & $11(64.7 \%)$ & $7(50 \%)$ & $>0.05$ \\
\hline Hypertension & 11 (35.5\%) & $6(35.2 \%)$ & $5(35.7 \%)$ & $>0.05$ \\
\hline DM & $7(22.5 \%)$ & $5(29.4 \%)$ & $2(14.2 \%)$ & $>0.05$ \\
\hline CAD & $1(3 \%)$ & $1(5 \%)$ & 0 & $>0.05$ \\
\hline RWMA & $1(3 \%)$ & $1(5 \%)$ & 0 & $>0.05$ \\
\hline Asthma & $1(3 \%)$ & 0 & $1(7 \%)$ & $>0.05$ \\
\hline COPD & $1(3 \%)$ & 0 & $1(7 \%)$ & $>0.05$ \\
\hline RHD & $1(3 \%)$ & $1(5 \%)$ & 0 & $>0.05$ \\
\hline LAD & $3.9 \pm 0.2$ & $4 \pm 0.2$ & $3.9 \pm 0.2$ & $>0.05$ \\
\hline Normal PV & $22(70 \%)$ & $12(70.6 \%)$ & $10(71.4 \%)$ & $>0.05$ \\
\hline Abnormal PV & $9(29 \%)$ & $5(29 \%)$ & $4(28 \%)$ & $>0.05$ \\
\hline Right $P V$ anomaly & & $2(11.8 \%)$ & $1(7.1 \%)$ & $>0.05$ \\
\hline Lt common os & & $3(17.6 \%)$ & $3(21.4)$ & \\
\hline LVEF & $58.2 \pm 5.5$ & $57.5 \pm 5.7$ & $59 \pm 5.2$ & $>0.05$ \\
\hline
\end{tabular}




\section{Analysis of primary endpoint}

Our study showed that segmental ablation is not inferior to circumferential ablation as an effective method for ablation for PAF over the follow-up period of 1 year (Figure 7). Atrial fibrillation recurred in 2 out of 14 patients $(14.3 \%)$ in the segmental ablation group, compared to 3 out of 17 patients (17.6\%) who were circumferentially ablated. This difference was statistically insignificant $(p<0.05)$.

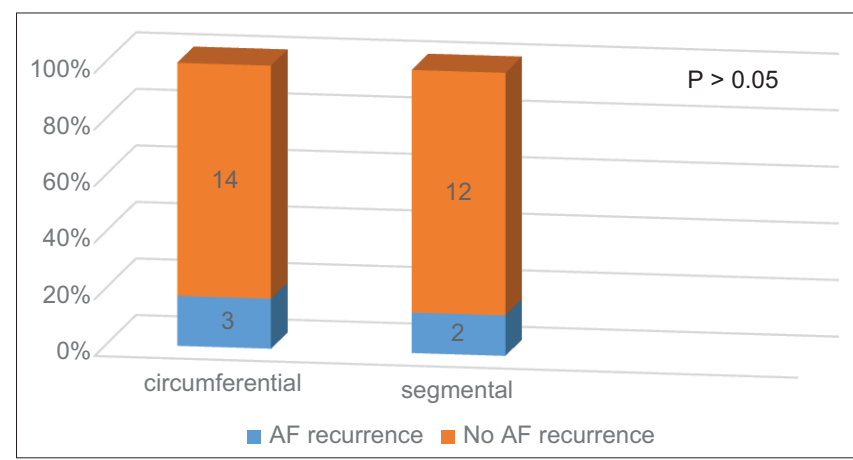

Figure 7: Effect of circumferential and segmental ablation on atrial fibrillation recurrence

Regarding mapping time (Figure 8), circumferential versus segmental was: $23.59 \pm 6.19 \mathrm{~min}$ versus $24.14 \pm 5.26 \min p=0.793$.

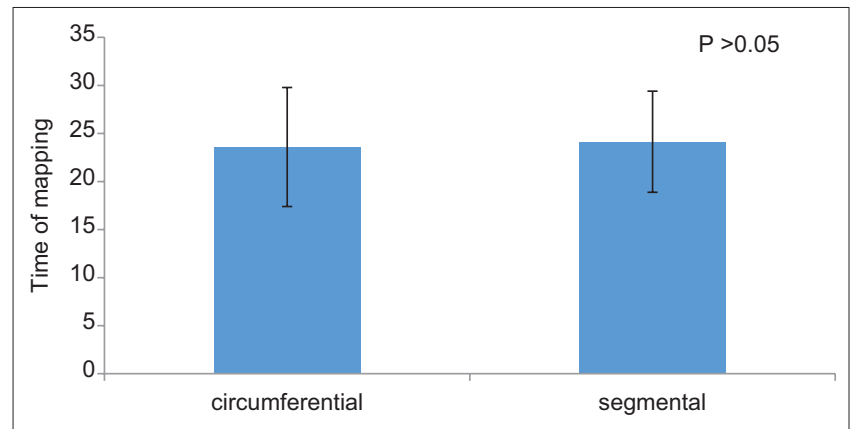

Figure 8: Mapping time in the conventional group compared to the segmental group

Radiofrequency ablation time was longer in the circumferential group, although there was no statistically significant difference.

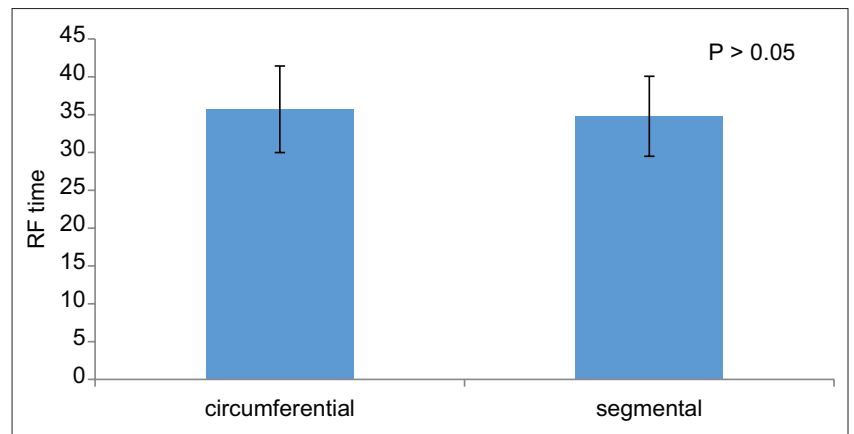

Figure 9: Radiofrequency ablation time in the conventional group compared to the segmental group

Circumferential versus segmental group was $35.71 \pm 5.73 \mathrm{~min}$ versus $34.79 \pm 5.29 \mathrm{~min} p=0.649$ (Figure 9).
Furthermore, there was no statistical difference between segmental and conventional group concerning procedure and fluoroscopy time, $184.18 \pm 19.28 \mathrm{~min}$ versus $191.43 \pm 20 \mathrm{~min}, \mathrm{p}=0.315$ (Figure 10) and $53.47 \pm 8.7 \mathrm{~min}$ versus $54.93 \pm 15.02 \mathrm{~min}, \mathrm{p}=0.738$ (Figure 11), respectively.

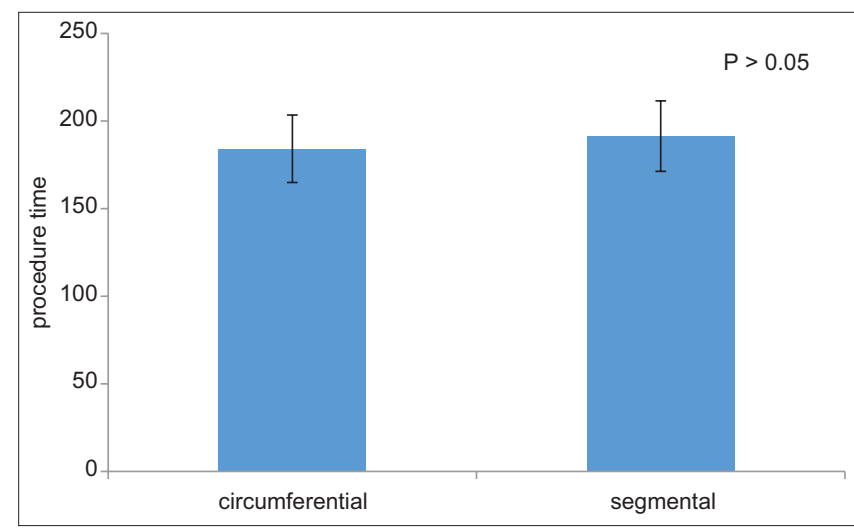

Figure 10: Mapping time in the conventional group compared to the segmental group

\section{Post-ablation complications}

Comparison between

early (pericardial tamponade) and late complications (postablation atrial flutter or atrial tachycardia) in both groups, there was no difference.

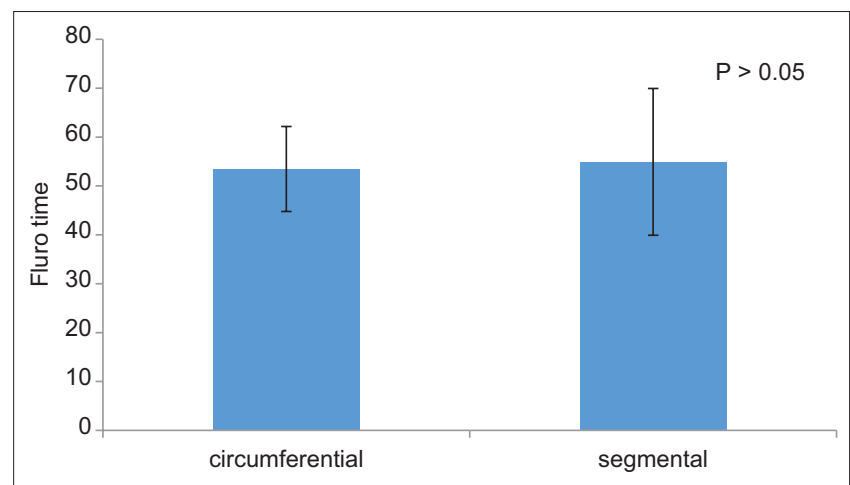

Figure 11: Fluoroscopy time in conventional group compared to segmental group

\section{Pericardial tamponade}

Cardiac tamponade was diagnosed by a reduction in the excursion of the cardiac silhouette on fluoroscopy with a simultaneous fall in systemic BP.

All cases were drained by pigtail catheter inside EP lab using epicardial puncture under the guidance of fluoroscopy. We used protamine IV injection depending on the dosage and the last time of heparin injection, for all patients after drainage.

After $24 \mathrm{~h}$, pigtail catheter was removed after confirmation of drained pericardium, by echocardiography, and patients were discharged. 
Table 2: Pulmonary vein mapping techniques

\begin{tabular}{llll}
\hline Mapping technique & 3D mapping circumferential & 17 & $100.0 \%$ \\
\hline & 3D mapping segmental & 8 & $57.1 \%$ \\
lasso segmental & 6 & $42.9 \%$ \\
\hline
\end{tabular}

\section{Pericarditis}

Tamponading patient in Group II (circumferential ablation) developed pericarditis that was controlled by steroid (prednisone $20 \mathrm{mg}$ with gradual tapering within 3 weeks).

Table 3: Insignificant difference between segmental and conventional ablation groups regarding procedure data

\begin{tabular}{|c|c|c|c|}
\hline \multirow[t]{2}{*}{ Procedure data } & \multicolumn{3}{|l|}{ Group } \\
\hline & $\begin{array}{l}\text { Group I (Circumferential } \\
\text { ablation) }\end{array}$ & $\begin{array}{l}\text { Group II } \\
\text { (Segmental ablation) } \\
\end{array}$ & $p$ \\
\hline Time of mapping & $23.59 \pm 6.19$ & $24.14 \pm 5.26$ & $>0.05$ \\
\hline Radio frequency time & $35.71 \pm 5.73$ & $34.79 \pm 5.29$ & $>0.05$ \\
\hline Procedure time & $184.18 \pm 19.28$ & $191.43 \pm 20.10$ & $>0.05$ \\
\hline Fluoroscopy time & $53.47 \pm 8.70$ & $54.93 \pm 15.02$ & $>0.05$ \\
\hline
\end{tabular}

\section{PV stenosis}

We did not have any case diagnosed clinically as PV stenosis (unexplained cough, and dyspnea).

\section{Predictors of recurrence}

Several clinical variables have been analyzed aiming at identifying possible predictors of $\mathrm{AF}$ recurrence after ablation (Tables 4 and 5).

Table 4: Post-atrial fibrillation complication in Group I (Circumferential ablation) and Group II (segmental ablation)

\begin{tabular}{lllll}
\hline Complications & \multicolumn{1}{l}{ Group I (\%) } & & Group II (\%) & $\mathrm{p}$ \\
\cline { 2 - 2 } & Total (17) & & Total (14) & \\
\hline Pericardial tamponade pericarditis & $1(5.8)$ & & $1(7.1)$ & $>0.05$ \\
Post ablation A.Flu/AT & $1(5.8)$ & & $0(0)$ & \\
Total complications & $3(17.6)$ & & $0(0)$ & $>0.05$ \\
\cline { 1 - 2 } & $4(23)$ & $1(7)$ & $>0.05$ \\
\hline
\end{tabular}

Of the clinical variables, the only recurrence in blanking period (Table 5) was seen prevalent in the AF recurrence group.

Table 5: Categorical variables for predicting atrial fibrillation recurrence

\begin{tabular}{|c|c|c|c|c|}
\hline \multirow[t]{3}{*}{ Categorical variables } & \multirow{3}{*}{ Count } & \multicolumn{3}{|c|}{ Recurrence after 1 year } \\
\hline & & Yes & No & $\mathrm{p}$ \\
\hline & & Count (\%) & Count (\%) & \\
\hline \multirow[t]{2}{*}{ Sex } & Male (18) & $2(40)$ & $16(61.5)$ & $>0.05$ \\
\hline & Female (13) & $3(60)$ & $10(38.5)$ & \\
\hline \multirow[t]{2}{*}{ HTN } & Yes (11) & $2(40)$ & $9(34.6$ & $>0.05$ \\
\hline & No $(20)$ & $3(60)$ & $17(65.4)$ & \\
\hline \multirow[t]{2}{*}{ Diabetes mellitus } & Yes (7) & $1(20)$ & $6(23.1)$ & $>0.05$ \\
\hline & No (24) & $4(80)$ & $20(76.9)$ & \\
\hline \multirow[t]{2}{*}{$\mathrm{IHD}$} & Yes (1) & $0(0)$ & $1(3.8)$ & $>0.05$ \\
\hline & No $(30)$ & $5(100)$ & $25(96.2)$ & \\
\hline \multirow[t]{2}{*}{ Asthma } & Yes (1) & $0(0)$ & $1(3.8)$ & $>0.05$ \\
\hline & No $(30)$ & $5(100)$ & $25(96.2)$ & \\
\hline \multirow[t]{2}{*}{ COPD } & Yes (1) & $0(0)$ & $1(3.8)$ & $>0.05$ \\
\hline & No $(30)$ & $5(100)$ & $25(96.2)$ & \\
\hline \multirow[t]{2}{*}{ RHD } & Yes (1) & $0(0)$ & $1(3.8)$ & $>0.05$ \\
\hline & No $(30)$ & $5(100)$ & $25(96.2)$ & \\
\hline \multirow[t]{2}{*}{ Anatomy of PV } & Normal (23) & $4(80)$ & $18(69.2)$ & $>0.05$ \\
\hline & Abnormal (9) & $1(20)$ & $8(30.8)$ & \\
\hline Recurrence in blanking period & Yes (2) & $2(100)$ & $0(0)$ & 0.02 \\
\hline ( $1^{\text {st }} 3$ months) & No (29) & $3(10.3)$ & $26(89.7)$ & \\
\hline
\end{tabular}

Analysis of correlation between LA anteroposterior diameter (LAD), and fluoroscopy time Figure 12, mapping time Figure 13, and radiofrequency time Figure 14, was no significant.

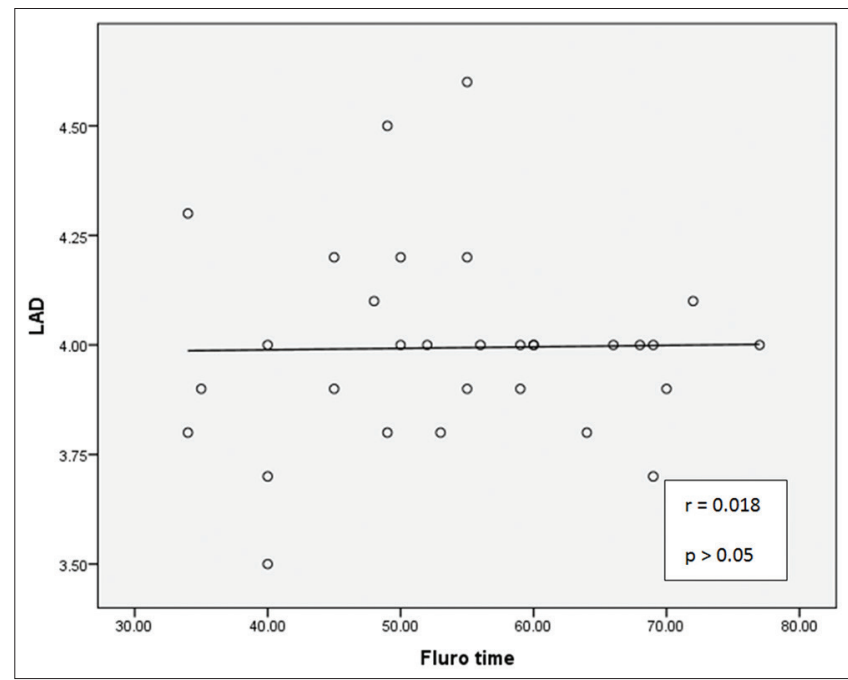

Figure 12: Relationship between left atrium diameter and fluoroscopy time

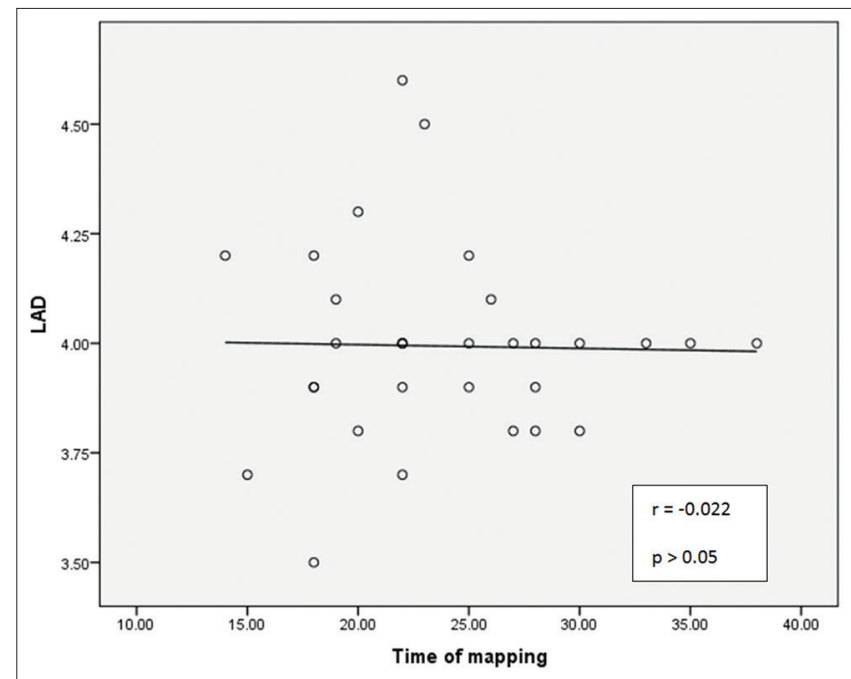

Figure 13: Relationship between left atrium diameter and mapping time

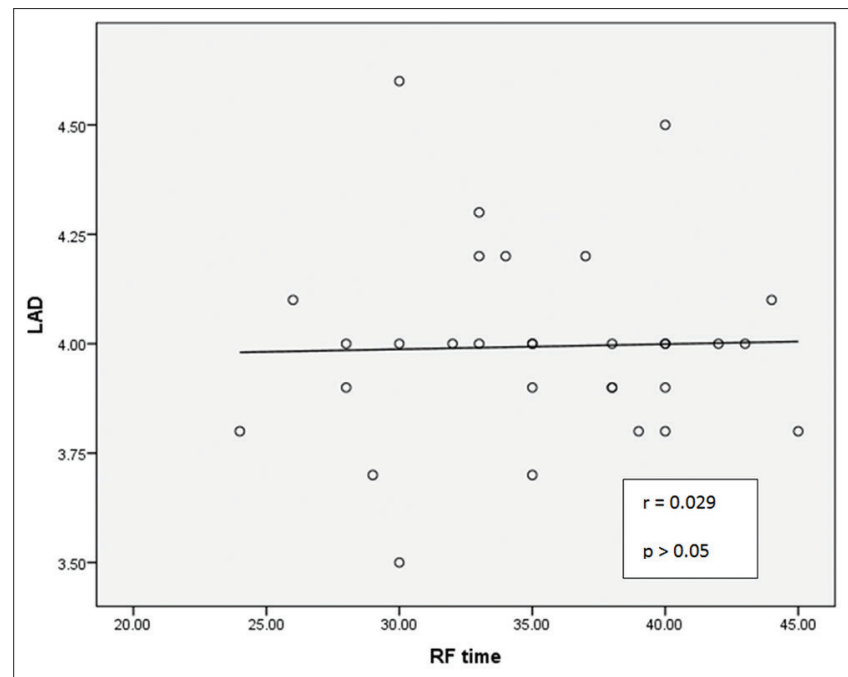

Figure 14: Relationship between left atrium diameter and radiofrequency time 
Table 6: Numerical variables for predicting of atrial fibrillation recurrence

\begin{tabular}{|c|c|c|c|}
\hline \multirow[t]{3}{*}{ Numerical variables } & \multicolumn{2}{|c|}{ Recurrence 1 year } & \multirow[t]{3}{*}{$p$} \\
\hline & Yes & No & \\
\hline & Mean \pm SD & Mean \pm SD & \\
\hline Age & $50.80 \pm 3.90$ & $54.54 \pm 5.97$ & $>0.05$ \\
\hline LAD & $4.12 \pm 0.26$ & $3.97 \pm 0.21$ & $>0.05$ \\
\hline
\end{tabular}

Table 7: Relationship between pulmonary veins abnormal anatomy and mapping, RF, procedure, and fluoroscopy time

\begin{tabular}{|c|c|c|c|c|}
\hline \multirow{3}{*}{$\begin{array}{l}\text { Numerical } \\
\text { variables }\end{array}$} & \multicolumn{3}{|l|}{ Anatomy of PV } & \multirow[t]{3}{*}{$p$} \\
\hline & Normal & Lt common os & Rt PV anomaly & \\
\hline & Mean \pm SD & Mean \pm SD & Mean \pm SD & \\
\hline Time of mapping & $22.73 \pm 4.62$ & $24.67 \pm 7.47$ & $30.33 \pm 6.66$ & $>0.05$ \\
\hline RF time & $36.91 \pm 5.07$ & $31.33 \pm 2.94$ & $31.33 \pm 7.57$ & 0.03 \\
\hline procedure time & $189 \pm 21.16$ & $180.83 \pm 15.13$ & $189.33 \pm 19.14$ & $>0.05$ \\
\hline Fluoro time & $56.41 \pm 11.08$ & $52.5 \pm 12.72$ & $40.67 \pm 7.02$ & $>0.05$ \\
\hline
\end{tabular}

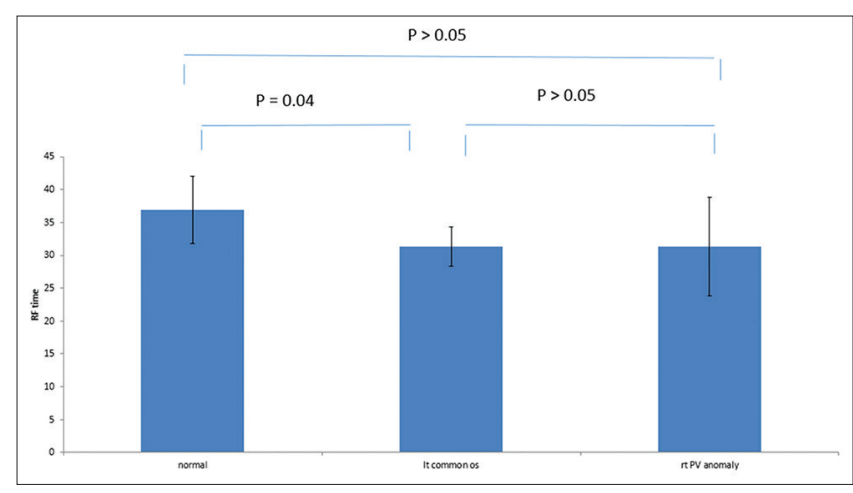

Figure 15: Post hoc analysis for relation of radio frequency (RF) time and abnormal anatomy of pulmonary veins showed left common ostium as an independent factor for decreasing of RF time

Correlation between abnormal anatomy of PVs in form of left common os (6 patients, 19.4\%) and accessory of right PVs (3 patients, 9.7\%), showed lesser radiofrequency time without affecting mapping, fluoroscopy, and procedure time.

\section{Discussion}

There is no doubt that AF is the disease of the present and the future, we have understood a lot about its pathogenesis and management, but we are still missing the complete cure, although in last few years, we have a technological revolution with many evolving hypotheses and new techniques for managing AF.

Long story of struggle starting by Cox et al. [13] with the first step of success in early 1990 by the introduction of MAZE-3 [13], [14] which motivated the scientific staff for adopting the same surgical concept for catheter ablation.

Second success and most important station in AF ablation history were done by Haïssaguerre et al. by the identification of PVs as the site of triggers for AF [15], then an ablation strategy of encircling the PVs guided by 3D electroanatomical mapping was subsequently developed by Pappone et al. [16].

However, there is controversy in the literature regarding the most effective approach (i.e. segmental vs. circumferential) to achieve durable PVI and ensure long-term success in preventing recurrence of AF. In fact, there is no definitive prospective randomized study published to date, with a large enough population of patients, over an acceptable duration of follow-up, and with adequate monitoring to ensure identification of $A F$ recurrence, which convincingly proves one method as being superior to achieve durable PVI and long-term suppression of AF [17].

\section{Effectiveness of segmental versus circumferential ablation of AF on recurrence}

Ablation of the triggers at PVs was either performed segmentally, guided by a circular mapping catheter [18] positioned close to the PV ostium, the so called segmental PV ablation or by wider continuous circumferential ablation lesions created to surround the right or left PVs [19] the so-called wide area circumferential ablation (WACA).

In our study, we compared between WACA and extra -ostial or antral segmental ablation. One of the primary endpoints was the effectiveness of both strategies on recurrence after 12 months of follow.

Atrial fibrillation recurred in 2 out of 14 patients $(14.3 \%)$ in the segmental ablation group, compared to 3 out of 17 patients $(17.6 \%)$ who were circumferential ablated, $(p>0.05)$. Accordingly, segmental is not inferior to circumferential PVs ablation.

Several studies have been published comparing segmental with circumferential PVI for the treatment of AF. In one such study by Karch et al. [20], 100 patients with symptomatic AF were randomized to either circumferential $(n=50)$ or segmental $(n=50)$, and freedom from atrial tachyarrhythmias was assessed using a 7-day Holter monitor at 6 months follow-up. Twenty-one patients (42\%) were free from any atrial tachyarrhythmias, including AF after circumferential and 33 patients $(66 \%)$ after segmental $(p=0.02)$.

This study result is supported later with other studies, as in a study of 80 patients with PAF performed by Mansour et al. [21] 40 patients underwent segmental PVI, and 40 patients underwent circumferential PVI. At $11 \pm$ 2.5 months, 24 patients $(60 \%)$ who underwent segmental and 30 patients $(75 \%)$ underwent circumferential were free of symptomatic PAF. There was no statistically significant difference between the two approaches for PVI.

Worth mentioning, in this study, additional ablation lines were done at the mitral isthmus with the circumferential approach.

Fiala et al. [22] suggested that circumferential $\mathrm{PVI}$ would improve the outcome in patients with PAF 
comparing to the segmental approach. Fifty-four patients underwent segmental (Group 1) and 56 patients underwent circumferential (Group 2), in a randomized study with follow-up for $48 \pm 8$ months. After a single procedure, 30 patients (56\%) in Group 1 and 32 patients $(57 \%)$ in Group 2 remained free of arrhythmia $(p=0.41)$. The authors concluded that there was no advantage in long-term arrhythmia free clinical outcomes after circumferential versus segmental RF ablation in PAF.

In contrast to our results, some other studies showed the superiority of circumferential versus segmental $\mathrm{PVI}$ approach in AF patients.

Oral et al. [23] studied 80 consecutive patients with symptomatic PAF, of whom 40 underwent PVI by segmental ablation and 40 underwent circumferential ablation. At 6 months, $67 \%$ of patients who underwent segmental and $88 \%$ of patients who underwent circumferential were free of symptomatic PAF $(p=0.02)$.

In this study, additional linear ablation was performed at the mitral isthmus connecting the mitral valve annulus to the left circumferential lesion and at the posterior LA connecting the left and right circumferential ablation lesions (box isolation) which could interpret this significant difference in favor of circumferential ablation in which decreasing LA critical mass by isolation of posterior wall of LA.

In Nilsson et al., study [24] that included 100 patients with symptomatic AF, 54 patients were randomized for segmental ablation and 46 patients for the circumferential group. During a mean follow-up of 12 months without antiarrhythmic drugs, $57 \%$ of patients who underwent circumferential $\mathrm{PV}$ isolation were free of arrhythmia symptoms compared to $31 \%$ of patients who underwent segmental ablation $(p<0.05)$.

This difference in success rate between the two ablation strategies was mainly seen, however, in patients with known persistent AF $(52 \%$ vs. $15 \%$; $\mathrm{p}=0.02)$, as opposed to patients with PAF (65\% vs. $46 \% ; p=0.26)$.

\section{Procedure time, fluoroscopic time, mapping time, and RF ablation time}

In our study, there was no statistically significant difference between circumferential versus segmental regarding fluoroscopy time, $53.47 \pm 8.7 \mathrm{~min}$ versus $54.93 \pm 15.02 \mathrm{~min}, \mathrm{p}>0.05$, procedure time, $184.18 \pm$ 19.28 min versus $191.43 \pm 20 \mathrm{~min}, \mathrm{p}>0.05$, and even for RF time which was lower in segmental group but did not differ statistically, $35.71 \pm 5.73 \mathrm{~min}$ versus $34.79 \pm$ $5.29, \min p>0.05$.

In large meta-analysis comparing between circumferential and segmental ablation, published in 2014 [25], data on total procedure duration and fluoroscopy time were reported in Calkins et al. [8], [22], [26], [27], [28], [29], [30], and [10], [21], [23], [24], [26],
[27], [28], [31], [22], [30], [32] studies, respectively.

Overall, the total procedure duration was significantly longer in the circumferential group than that in the segmental PVI group, (mean difference, $17.22 \mathrm{~min} 95 \% \mathrm{Cl}, 11.09-23.34)$, whereas the total fluoroscopy time was significantly reduced, mean difference, $-9.25 \min (95 \% \mathrm{Cl},-10.50--8.01)$. Radiofrequency application time was reported in PerezLugones et al. [9], Mansour et al. [21], Oral et al. [23], Nilsson et al. [24], Liu et al. [26], Arentz et al. [27], Jin Hwang et al. [28], Sawhney et al. [31], Tan et al. [30], Yamane et al. [32] studies. The circumferential group had longer times mean difference, $11.87 \min (95 \% \mathrm{Cl}$, 10.45-13.30 $\mathrm{min})$.

To the best of our knowledge, there is no study that includes mapping time as a comparable item, which is defined in our study as the time from inserting circular map till definition of all PVs. Our statistics showed there was no difference between circumferential versus segmental ablation, $23.59 \pm 6.19$ min versus $24.14 \pm$ $5.26 \min p>0.05$

\section{LA size and PVs anomalies and effect on mapping, fluoroscopy, and ablation time}

The LA diameter (anteroposterior size, $3.99 \pm$ $0.22 \mathrm{~cm}$ ), had no relation or any effect on fluoroscopy, mapping, and RF ablation time, for three items, $p>0.05$

It was not the same for PVs anatomy, as abnormal PV anatomy in the form of left common ostium (6 patients, 19.4\%), or accessory right PVs (3 patients, 9.7\%) affected significantly radiofrequency ablation (normal anatomy, left common ostium, and right accessory PVs, RF time was $36.91 \pm 5.07,31.33$ \pm 2.94 , and $31.33 \pm 7.57$, respectively, $p<0.05$ ) without affecting mapping $(p>0.05)$ or fluoroscopic time $(p>0.05)$.

Sub statistical analysis showed left common ostium as accused factor for affecting RF ablation time, and it can be interpreted as it is more feasible to ablate one ostium, also missing the carina, which is one of the difficult sites of LA ablation, saves some time.

Actually, most of the studies discussing the effect of LA anatomy and, especially abnormal PVs, were concerning AF ablation outcome and not focusing on procedure data.

In a study published in 2017 by Stabile et al., [33] and was done on 75 patients (mean age $58 \pm 11$ years, $67 \%$ male) for symptomatic PAF ablation.

The mean LA volume was $75 \pm 40 \mathrm{ml}$. A normal anatomy (4 PVs) was documented in 40 (53\%) patients and abnormal anatomy (common ostium or accessory PVs) in 35 patients. Mean procedural and fluoroscopy times were $94 \pm 55$ and $8 \pm 5$ min, respectively, without significant differences among patients with normal or abnormal anatomy (92 \pm 45 vs. $95 \pm 64 \mathrm{~min}, \mathrm{p}=0.85$ 
and $6 \pm 3$ vs. $8 \pm 4 \min , p=0.65$, respectively). The mean ablation time was $14 \pm 3 \mathrm{~min}$. Their conclusion was, there was no effect regarding LA volume and PV anatomy on procedural data and outcome.

\section{Post-ablation complications}

\section{Pericardial tamponade}

In our study, we had two patients $(6 \%)$ complicated with pericardial tamponade, one in each group, $(p>0.05)$. Two patients were females, and both had stem pop during ablation.

Our percentage is higher than normal incidence, according to a recent paper by Deshmukh et al. [34] reported between 2000 and 2010, the overall incidence of a "pericardial complication" was $1.5 \%$. The incidence of pericardial complications increased from $0.74 \%$ in 2000 to $2.24 \%$ in 2010 .

This study was on nationwide sample involving 93,801 procedures and cannot be compared statistically with our limited number study. Nevertheless, in prospective European surveys on AF ablation [35], the incidence of tamponade was high as $6 \%$.

One of the risk factors that increasing the incidence of cardiac tamponade is female sex. Women were 1.83-fold more likely to develop tamponade compared with men [8].

Steam pop developed in a result of RF overheating mainly. Excessive power, temperature, and contact force may be contributory factors.

In our study, we had 5 patients in whom (steam pop) were recorded, but only one had pericardial effusion.

Cappato et al. [36] reported a large series with cardiac tamponade during 15 of 632 AF ablation procedures $(2.4 \%)$. Two of these patients required surgical intervention, and no "pop" was reported.

\section{Pericarditis}

The patient who had tamponade in circumferential group developed pericarditis 1 week post-ablation.

Pericarditis is a self-limited manifestation post-AF ablation and considered as a standards clinical course; it percentage $0 \%$ up to $50 \%$, [8].

According to 2017 HRS/EHRA/ECAS/APHRS/ SOLAECE expert consensus statement on catheter and surgical ablation of AF [8], it should be considered a major complication following ablation if it results in an effusion with hemodynamic compromise or requires pericardiocentesis, or prolongs hospitalization more than $48 \mathrm{~h}$, requires hospitalization, or persists for more than 30 days following the ablation procedure, which is not the case in our study.

\section{Post-AF ablation atrial tachyarrhythmia}

In our study, although we had 3 patients with post-ablation tachyarrhythmia belonging to the circumferential group, in whom there were no additional ablation lines, our statistics showed no significant difference between 2 groups $(p>0.05)$

In fact, it is known that circumferential ablation is often complicated with atrial tachyarrhythmia, mainly due to adding of linear ablation such as roof, mitral isthmus, or anterior line; nevertheless, in other studies circumferential ablation with or without linear ablation has been associated with development of the left atrial tachyarrhythmia [37], [38], [39], which is rarely seen after segmental ablation alone [40].

Nilsson et al. [24] performed ablation in 180 patients with persistent AF. Patients were divided into two groups: (Group A) those who did not require additional linear ablation to terminate AF (85 patients) and (Group B) those who did (69 patients). After 28 months follow-up, the incidence of left atrial tachyarrhythmias necessitating repeat or additional linear ablation was higher in Group A $(76 \%)$ compared to Group B $(33 \%)(p=0.002)$.

In a randomized, prospective study by Sawhney et al. [31], all patients were under follow-up every 6 months with continuous ECG monitoring for 14 days, atypical atrial flutters were more in circumferential with linear ablation group than segmental group $(p=0.002)$.

In a meta-analysis published by Proietti et al. [25], they analyzed seven studies [23], [24], [26], [27], [30], [31], [32]s that assessed atrial tachycardia recurrence as a separate outcome. A trend toward a higher incidence of LA tachycardia occurrence in the WACAgroup was detected, which did not reach statistical significance (OR, 1.53; 95\% Cl, 0.88-2.69; $\mathrm{p}=0.13$ ) although AF recurrence was lower.

\section{Blanking period AF recurrence as a predicting factor for long-term outcome}

Only predicting factor in our study for AF recurrence post-ablation was the early recurrence in the blanking period, which is defined as first 3 months post-catheter ablation $(p<0.05)$.

Recurrence within 3 months following catheter ablation is relatively common predictor of late recurrence, although different definitions of the item of early recurrence [41], [42], [43], [44], [45], [46], [47], [48], [49], [50].

Arya et al. [45] defined early recurrence as a sustained episode of AF within 7 days immediately after the procedure, while others defined it by a sustained episode of AF within 2 weeks [41], 1 month, [42], [43] 6 weeks, [44], [50], and 3 months [46], [47], [48], [49] during the blanking period.

A recent study in 2017 by Xue et al. [51] included prospectively 378 patients for paroxysmal or persistent 
AF initial ablation. After a mean follow-up of $14.71 \pm$ 8.58 months, $81(65.90 \%)$ patients with early recurrence (defined as first 7 days post-ablation) experienced late recurrence and were associated with the lower event of free survival from late recurrence $(p<0.001)$.

Worth mentioning, in the same study [51], they concluded that left atrial size (enlargement), elderly, and male sex were independent factors for recurrence, in contrast to our study.

The use of 3-months blanking period has been proposed on the assumption that early recurrence will lead to a delayed cure and should not prompt immediate re-ablation attempts [52], [53], [54].

Mechanisms of arrhythmia recurrence within 3 months of post-ablation remain to be fully elucidated and may include reconnection of the PVs [55], inflammatory response to thermal injury and/ or pericarditis, imbalance of the autonomic nervous system [56], and a delayed effect of AF ablation [57].

\section{Limitation}

Nevertheless, in our prospective randomized study, we were very strict about inclusion and exclusion criteria, good selection of homogeneous patient criteria in both groups, and eradication of all potential biases that can affect our results, but our study is still limited due to:

1. Limited number due to inclusion criteria contained Pakistan air force, and long-time of follow-up (at least 12 months)

2. Different operators, which can be considered as a heterogeneity due to a small sample

3. Differentmapping systems, and ablation catheters with different characteristics (e.g., contact force)

4. Deficiency of long monitoring devices (e.g., intracardiac loop recorder), and we depended mainly on ECG Holter $48-72 \mathrm{~h}$ as a routine for asymptomatic cases, and documented ECG or Holter for symptomatic cases

5. Pulmonary venography was not listed as a routine imaging tool post-ablation to exclude $\mathrm{PV}$ stenosis because we depended primary on clinical manifestation (unexplained cough and dyspnea).

In any way according to last American AF guidelines 2017 [8], even there is a PV stenosis but asymptomatic and does not need intervention (surgically or stenting) not considered as a complication.

\section{Conclusions}

Atrial fibrillation is an independent risk factor causing mortality and its management is still missing full cure, although rapidly evoked advanced technology, last years.

However, many theories for the best method of AF ablation, $\mathrm{PVI}$ remained the cornerstone and an indispensable step in any method.

There is no definitive, prospective, randomized study published to date, with a large enough population of patients, over an acceptable duration of follow-up, and with adequate monitoring to ensure identification of AF recurrence comparing segmental versus circumferential ablation method.

In our study, we had tried to get away from all biases that were found in publications to have clear definitive results regarding both methods.

In the circumferential ablation group, we were very strict about no adding of any linear ablations, which are unfair and intolerable factor affecting long-term outcomes and causing post-ablation tachyarrhythmia.

Furthermore, in the segmental group, we tried - what we called - extra ostial ablation not to be complicated with PV stenosis.

No surprise, there are some centers still adopting segmental ablation as standard method for PAF ablation even primary or redo, as some centers in France and in Japan where segmental ablation is modified to be for anterior wall with linear RF on the posterior wall.

Nevertheless, the similarity of our results to a published abstract in last APHRS 2018 with retrospective long-term (10 years) follow-up study of comparison between segmental and circumferential PV isolation, we are waiting for the results of the clinical trial of effectiveness study of circumferential versus segmental ablation in PAF that is recorded by ClinicalTrials.gov Identifier: NCT02106663.

It is started by Gregory Kent Feld, University of California, San Diego, in July 2012 and expected to be released in May 2020.

\section{Recommendations}

We can use extra-ostial segmental ablation of PVs safely specifically in cases where circumferential ablation is not feasible due to the unavailability of 3D electro-anatomical mapping or in redo cases in which reconnection points of PVs are the target

Segmental ablation is as effective as circumferential ablation and decreases the incidence of evolving post-AF ablation atrial flutter

In segmental ablation, we should avoid ostial ablation by detection of PV ostium precisely. 


\section{References}

1. Cox JL, Schuessler RB, Lappas DG, Boineau JP. An 8 1/2year clinical experience with surgery for atrial fibrillation. Ann Surg. 1996;224(3):267-73. https://doi.org/10.1016/j. athoracsur.2015.09.055

\section{PMid:8813255}

2. Moe GK, Rheinboldt WC, Abildskov JA. A computer mode of atrial fibrillation. Am Heart J. 1964;67:200-20. https://doi. org/10.1016/0002-8703(64)90371-0

\section{PMid:14118488}

3. Padanilam BJ, Prystowsky EN. Should atrial fibrillation ablation be considered first-line therapy for some patients? Should ablation be first-line therapy and for whom? the antagonist position. Circulation. 2005;112(8):1223-9. https://doi. org/10.1161/circulationaha.104.483305

\section{PMid:16118843}

4. Chun KR, Bansch D, Ernst S, Ujeyl A, Huang $\mathrm{H}$, Chu $\mathrm{H}$, et al. Pulmonary vein conduction is the major finding in patients with atrial tachyarrhythmias after intraoperative maze ablation. J Cardiovasc Electrophysiol. 2007;18(4):358-63. https://doi. org/10.1111/j.1540-8167.2007.00771.x

\section{PMid:17313532}

5. Haïssaguerre $M$, Jaïs $P$, Shah DC, Takahashi $A$, Hocini M, Quiniou G, . Spontaneous initiation of atrial fibrillation by ectopic beats originating in the pulmonary veins. N Engl J Med. 1998;339(10):659-66. https://doi.org/10.1056/nejm199809033391003

PMid:9725923

6. Scherf D, Schaffer Al, Blumenfeld S. Mechanism of flutter and fibrillation. AMA Arch Intern Med. 1953;91(3):333-52 PMid:13029958

7. Kirchhof P, Benussi S, Kotecha D, Ahlsson A, Atar D, Casadei B, et al. 2016 ESC Guidelines for the management of atrial fibrillation developed in collaboration with EACTS. Europace. 2016;18(11):1609-78. https://doi.org/10.5603/kp.2016.0172 PMid:27567465

8. Calkins H, Hindricks G, Cappato R, Kim YH, Saad EB, Aguinaga L, et al. 2017 HRS/EHRA/ECAS/APHRS/SOLAECE expert consensus statement on catheter and surgical ablation of atrial fibrillation. Heart Rhythm. 2017;14(10):e275-444. https:// doi.org/10.1093/europace/euw260

PMid:28506916

9. Perez-Lugones A, Schvartzman PR, Schweikert R, Tchou PJ, Saliba W, Marrouche NF, et al. Three-dimensional reconstruction of pulmonary veins in patients with atrial fibrillation and controls: Morphological characteristics of different veins. Pacing Clin Electrophysiol. 2003;26(1 Pt 1):8-15. https://doi. org/10.1046/j.1460-9592.2003.00144.x

PMid:12685134

10. Chan YH. Biostatistics 102: Quantitative data--parametric and non-parametric tests. Singapore Med J. 2003;44(8):391-6. PMid: 14700417

11. Chan YH. Biostatistics 103: Qualitative data tests of independence. Singapore Med J. 2003;44(10):498-503. PMid:15024452

12. Chan YH. Biostatistics 104: Correlational analysis. Singapore Med J. 2003;44(12):614-9. PMid:14770254

13. Cox JL, Canavan TE, Schuessler RB, Cain ME, Lindsay BD, Stone $\mathrm{C}$, et al. The surgical treatment of atrial fibrillation. II. Intraoperative electrophysiologic mapping and description of the electrophysiologic basis of atrial flutter and atrial fibrillation.
J Thorac Cardiovasc Surg. 1991;101(3):406-26. https://doi. org/10.1007/bf02860878

PMid:1999934

14. Swartz JF, Pellersels G, Silvers J, Patten L, Cervantez D. A catheter-based curative approach to atrial fibrillation in humans. Circulation. 1994;90:335.

15. Haïssaguerre $M$, Jaïs $P$, Shah DC, Garrigue $S$, Takahashi $A$ Lavergne $T$, et al. Electrophysiological end point for catheter ablation of atrial fibrillation initiated from multiple pulmonary venous foci. Circulation. 2000;101(12):1409-17. https://doi. org/10.1161/01.cir.101.12.1409

PMid:10736285

16. Pappone C, Oreto G, Lamberti F, Vicedomini G, Loricchio ML, Shpun S, et al. Catheter ablation of paroxysmal atrial fibrillation using a 3D mapping system. Circulation. 1999;100(11):1203-8. https://doi.org/10.1161/01.cir.100.11.1203

17. Feld GK. Controversy: Circumferential versus segmental pulmonary vein isolation/segmental PVI, No. Group 1. 2015: 183-90. https://doi.org/10.1002/9781118658369.ch13b

18. Oral H, Knight BP, Ozaydin M, Chugh A, Lai SW, Scharf C et al. Segmental ostial ablation to isolate the pulmonary veins during atrial fibrillation: Feasibility and mechanistic insights. Circulation. 2002;106(10):1256-62. https://doi.org/10.1161/01. cir.0000027821.55835.00 PMid:12208802

19. Yamada T, Murakami $Y$, Okada T, Okamoto M, Shimizu T, Toyama $\mathrm{J}$, et al. Electrophysiological pulmonary vein antrum isolation with a multielectrode basket catheter is feasible and effective for curing paroxysmal atrial fibrillation: Efficacy of minimally extensive pulmonary vein isolation. Heart Rhythm. 2006;3(4):377-84. https://doi.org/10.1016/j.hrthm.2005.12.027 PMid: 16567281

20. Karch MR, Zrenner B, Deisenhofer I, Schreieck J, Ndrepepa G, Dong $\mathrm{J}$, et al. Freedom from atrial tachyarrhythmias after catheter ablation of atrial fibrillation: A randomized comparison between 2 current ablation strategies. Circulation. 2005;111(22):2875-80. https://doi.org/10.1161/circulationaha.104.491530 PMid: 15927974

21. Mansour M, Ruskin J, Keane D. Efficacy and safety of segmental ostial versus circumferential extraostial pulmonary vein isolation for atrial fibrillation. J Cardiovasc Electrophysiol. 2004;15(5):532-7. https://doi. org/10.1046/j.1540-8167.2004.03503.x PMid: 15149421

22. Fiala M, Chovancík J, Nevralová R, Neuwirth R, Jiravský $O$ Nykl I, et al. Pulmonary vein isolation using segmental versus electroanatomical circumferential ablation for paroxysmal atrial fibrillation: Over 3-year results of a prospective randomized study. J Interv Card Electrophysiol. 2008;22(1):13-21. https:// doi.org/10.1007/s10840-008-9212-7

PMid:18418704

23. Oral H, Scharf $\mathrm{C}$, Chugh A, Hall B, Cheung P, Good E, et al Catheter ablation for paroxysmal atrial fibrillation: Segmental pulmonary vein ostial ablation versus left atrial ablation. Circulation. 2003;108(19):2355-60. https://doi.org/10.1161/01. cir.0000095796.45180.88

\section{PMid: 14557355}

24. Nilsson B, Chen X, Pehrson S, Køber L, Hilden J, Svendsen JH Recurrence of pulmonary vein conduction and atrial fibrillation after pulmonary vein isolation for atrial fibrillation: A randomized trial of the ostial versus the extraostial ablation strategy. Am Heart J. 2006;152(3):537.e1-8. https://doi.org/10.1016/j. ahj.2006.05.029

PMid: 16923426

25. Proietti R, Santangeli P, Di Biase L, Joza J, Bernier ML, Wang $Y$, et al. Comparative effectiveness of wide antral versus 
ostial pulmonary vein isolation: A systematic review and metaanalysis. Circ Arrhythm Electrophysiol. 2014;7(1):39-45. https:// doi.org/10.1161/circep.113.000922

PMid:24385448

26. Liu X, Long D, Dong J, Hu F, Yu R, Tang R, et al. Is circumferential pulmonary vein isolation preferable to stepwise segmental pulmonary vein isolation for patients with paroxysmal atrial fibrillation? Circ J. 2006;70(11):1392-7. https://doi.org/10.1253/ circj.70.1392

PMid:17062959

27. Arentz T, Weber R, Bürkle G, Herrera C, Blum T, Stockinger J, et al. Small or large isolation areas around the pulmonary veins for the treatment of atrial fibrillation? Results from a prospective randomized study. Circulation. 2007;115(24):3057-63. https:// doi.org/10.1161/circulationaha.107.690578 PMid:17562956

28. Jin Hwang H, Myung Lee J, Joung B, Lee BH, Kim JB, Lee MH, et al. Atrial electroanatomical remodeling as a determinant of different outcomes between two current ablation strategies: Circumferential pulmonary vein isolation vs pulmonary vein isolation. Clin Cardiol. 2010;33(3):E69-74. https://doi.org/10.1002/clc.20567 PMid:20127901

29. Yamada T, Yoshida N, Murakami Y, Okada T, Yoshida Y, Muto M, et al. The difference in autonomic denervation and its effect on atrial fibrillation recurrence between the standard segmental and circumferential pulmonary vein isolation techniques. Europace. 2009;11(12):1612-9. https://doi.org/10.1093/europace/eup330 PMid:19875397

30. Tan HB, Yang XL, Wen XT. Efficacy and safety of segmental pulmonary vein isolation and circumferential pulmonary vein isolation in patients with atrial fibrillation: A comparative study. Nan Fang Yi Ke Da Xue Xue Bao. 2009;29(1):128-32. https:// doi.org/10.1002/9781118658369.ch13b

PMid:19218132

31. Sawhney N, Anousheh R, Chen W, Feld GK. Circumferential pulmonary vein ablation with additional linear ablation results in an increased incidence of left atrial flutter compared with segmental pulmonary vein isolation as an initial approach to ablation of paroxysmal atrial fibrillation. Circ Arrhythm Electrophysiol. 2010;3(3):243-8. https://doi.org/10.1161/ circep.109.924878

PMid:20339034

32. Yamane T, Date T, Kanzaki Y, Inada K, Matsuo S, Shibayama K, et al. Segmental pulmonary vein antrum isolation using the "large-size" lasso catheter in patients with atrial fibrillation. Circ J. 2007;71(5):753-60. https://doi.org/10.1253/circj.71.753 PMid: 17457004

33. Stabile G, Anselmino M, Soldati E, De Ruvo E, Solimene F, Iuliano $A$, et al. Effect of left atrial volume and pulmonary vein anatomy on outcome of $\mathrm{nMARQ}{ }^{\mathrm{TM}}$ catheter ablation of paroxysmal atrial fibrillation. J Interv Card Electrophysiol. 2017;48(2):201-7. https://doi.org/10.1007/s10840-016-0189-3 PMid:27714605

34. Deshmukh A, Patel NJ, Pant S, Shah N, Chothani A, Mehta K, et al. In-hospital complications associated with catheter ablation of atrial fibrillation in the United States between 2000 and 2010: Analysis of 93801 procedures. Circulation. 2013;128(19):2104-12. https://doi.org/10.1161/circulationaha.113.003862 PMid:24061087

35. Themistoclakis S, Raviele A, China P, Pappone C, De Ponti R, Revishvili A, et al. Prospective European survey on atrial fibrillation ablation: Clinical characteristics of patients and ablation strategies used in different countries. J Cardiovasc Electrophysiol. 2014;25(10):1074-81. https://doi.org/10.1111/ jce.12462

PMid:24891043.
36. Cappato R, Calkins H, Chen SA, Davies W, lesaka Y, Kalman J, et al. Delayed cardiac tamponade after radiofrequency catheter ablation of atrial fibrillation: A worldwide report. J Am Coll Cardiol. 2011;58(25):2696-7. https://doi.org/10.1016/j.jacc.2011.09.028 PMid:22152959

37. Chugh A, Oral H, Lemola K, Hall B, Cheung P, Good E, et al. Prevalence, mechanisms, and clinical significance of macroreentrant atrial tachycardia during and following left atrial ablation for atrial fibrillation. Heart Rhythm. 2005;2(5):464-71. https://doi.org/10.1016/j.hrthm.2005.01.027

PMid: 15840468

38. Matsuo S, Wright M, Knecht S, Nault I, Lellouche N, Lim KT, et al. Peri-mitral atrial flutter in patients with atrial fibrillation ablation. Heart Rhythm. 2010;7(1):2-8. https://doi.org/10.1016/j. hrthm.2009.09.067 PMid: 19962945

39. Chae S, Oral H, Good E, Dey S, Wimmer A, Crawford T, et al. Atrial tachycardia after circumferential pulmonary vein ablation of atrial fibrillation: mechanistic insights, results of catheter ablation, and risk factors for recurrence. J Am Coll Cardiol. 2007;50(18):1781-7. https://doi.org/10.1016/ s0735-1097(10)60047-2

PMid: 17964043

40. Oral $\mathrm{H}$, Knight BP, Morady F. Left atrial flutter after segmental ostial radiofrequency catheter ablation for pulmonary vein isolation. Pacing Clin Electrophysiol. 2003;26(6):1417-9. https:// doi.org/10.1046/j.1460-9592.2003.t01-1-00202.x PMid: 12822760

41. Oral H, Knight BP, Ozaydin M, Tada H, Chugh A, Hassan S, et al Clinical significance of early recurrences of atrial fibrillation after pulmonary vein isolation. J Am Coll Cardiol. 2002;40(1):100-4. https://doi.org/10.1016/s0735-1097(02)01939-3

PMid:12103262

42. Lee SH, Tai CT, Hsieh MH, Tsai CF, Lin YK, Tsao HM, et al. Predictors of early and late recurrence of atrial fibrillation after catheter ablation of paroxysmal atrial fibrillation. J Interv Card Electrophysiol. 2004;10(3):221-6. https://doi. org/10.1023/b: jice.0000026915.02503.92

PMid:15133358

43. Lellouche $N$, Jaïs $P$, Nault $I$, Wright $M$, Bevilacqua $M$, Knecht $S$, et al. Early recurrences after atrial fibrillation ablation: Prognostic value and effect of early reablation. J Cardiovasc Electrophysiol. 2008;19(6):599-605. https://doi. org/10.1111/j.1540-8167.2008.01188.x

PMid:18462321

44. Leong-Sit P, Roux JF, Zado E, Callans DJ, Garcia F, Lin D, et al. Antiarrhythmics after ablation of atrial fibrillation (5A Study): Six-month follow-up study. Circ Arrhythm Electrophysiol. 2011;4(1):11-4. https://doi.org/10.1161/circep.110.955393 PMid:21076158

45. Arya A, Hindricks G, Sommer P, Huo Y, Bollmann A, Gaspar T, et al. Long-term results and the predictors of outcome of catheter ablation of atrial fibrillation using steerable sheath catheter navigation after single procedure in 674 patients. Europace. 2010;12(2):173-80. https://doi.org/10.1093/europace/eup331 PMid:19889688

46. Pokushalov E, Romanov A, Corbucci G, Bairamova S, Losik D, Turov $A$, et al. Does atrial fibrillation burden measured by continuous monitoring during the blanking period predict the response to ablation at 12-month follow-up? Heart Rhythm. 2012;9(9):1375-9. https://doi.org/10.1016/j.hrthm.2012.03.047 PMid:22449740

47. Kaitani K, Inoue K, Kobori A, Nakazawa Y, Ozawa T, Kurotobi T, et al. Efficacy of antiarrhythmic drugs short-term use after catheter ablation for atrial fibrillation (EAST-AF) trial. Eur Heart 
J. 2016;37(7):610-8. https://doi.org/10.1093/eurheartj/ehv501
PMid:26417061

Themistoclakis S, Schweikert RA, Saliba WI, Bonso A, Rossillo A, Bader G, et al. Clinical predictors and relationship between early and late atrial tachyarrhythmias after pulmonary vein antrum isolation. Heart Rhythm. 2008;5(5):679-85. https:// doi.org/10.1016/j.hrthm.2008.01.031

PMid: 18325850

49. Koyama T, Sekiguchi $\mathrm{Y}$, Tada H, Arimoto T, Yamasaki H, Kuroki K, et al. Comparison of characteristics and significance of immediate versus early versus no recurrence of atrial fibrillation after catheter ablation. Am J Cardiol. 2009;103(9):1249-54. https://doi.org/10.1016/j.amjcard.2009.01.010

PMid:19406267

50. Roux JF, Zado E, Callans DJ, Garcia F, Lin D, Marchlinski FE, et al. Antiarrhythmics after ablation of atrial fibrillation (5A study). Circulation. 2009;120(12):1036-40. https://doi.org/10.1161/ circulationaha.108.839639 PMid:19738139

51. Xue $\mathrm{Y}$, Wang $\mathrm{X}$, Thapa $\mathrm{S}$, Wang L, Wang J, Xu Z, et al. Very early recurrence predicts long-term outcome in patients after atrial fibrillation catheter ablation: A prospective study. BMC Cardiovasc Disord. 2017;17(1):109. https://doi.org/10.1186/ s12872-017-0533-2 PMid:28482812

52. Calkins $H$, Kuck $\mathrm{KH}$, Cappato R, Brugada J, Camm AJ, Chen SA, et al. 2012 HRS/EHRA/ECAS expert consensus statement on catheter and surgical ablation of atrial fibrillation: Recommendations for patient selection, procedural techniques, patient management and follow-up, definitions, endpoints, and research trial design. Europace. 2012;14(4):528-606. https:// doi.org/10.1016/j.hrthm.2011.12.016

PMid:22389422.

53. O'Donnell D, Furniss SS, Dunuwille A, Bourke JP. Delayed cure despite early recurrence after pulmonary vein isolation for atrial fibrillation. Am J Cardiol. 2003;91(1):83-5. https://doi. org/10.1016/s0002-9149(02)03005-9

PMid: 12505579

54. Bertaglia E, Stabile G, Senatore G, Zoppo F, Turco P, Amellone C, et al. Predictive value of early atrial tachyarrhythmias recurrence after circumferential anatomical pulmonary vein ablation. Pacing Clin Electrophysiol. 2005;28(5):366-71. https://doi. org/10.1111/j.1540-8159.2005.09516.x PMid: 15869666

55. Lubitz SA, Fischer A, Fuster V. Catheter ablation for atrial fibrillation. BMJ. 2008;336(7648):819-26. https://doi. org/10.1136/bmj.39513.555150.be

PMid: 18403546

56. Pappone C, Santinelli V, Manguso F, Vicedomini G, Gugliotta F, Augello $G$, et al. Pulmonary vein denervation enhances longterm benefit after circumferential ablation for paroxysmal atrial fibrillation. Circulation. 2004;109(3):327-34. https://doi. org/10.1161/01.cir.0000112641.16340.c7

PMid: 14707026

57. Hsieh MH, Chiou CW, Wen ZC, Wu CH, Tai CT, Tsai CF et al. Alterations of heart rate variability after radiofrequency catheter ablation of focal atrial fibrillation originating from pulmonary veins. Circulation. 1999;100(22):2237-43. https://doi. org/10.1161/01.cir.100.22.2237

PMid:10577997 